\title{
Coronavirus infection and nursing care for children and adolescents with cancer
}

\author{
Infecções por coronavírus e os cuidados de enfermagem direcionados a crianças e adolescentes com câncer
}

Infecciones por coronavirus y los cuidados de enfermería dirigidos a niños y adolescentes con cáncer

Fernanda Machado Silva-Rodrigues' ORCID: 0000-0002-8412-2333

Jennifer Kamila da Silva"

ORCID: 0000-0002-1715-4589

Adriana Maria da Silva Felix

ORCID: 0000-0002-3559-3729

'Santa Casa de São Paulo, Faculdade de Ciências Médicas. São Paulo, São Paulo, Brazil.

"Instituto de Oncologia Pediátrica, Grupo de Assistência ao Adolescente e à Criança com Câncer. São Paulo, São Paulo, Brazil.

How to cite this article:

Silva-Rodrigues FM, Silva JK, Felix AMS. Coronavirus infection and nursing care for children and adolescents with cancer. Rev Bras Enferm. 2021;74(Suppl 1): e20201049. https://doi.org/10.1590/0034-7167-2020-1049

Corresponding author: Fernanda Machado Silva-Rodrigues E-mail: fernanda.rodrigues@fcmsantacasasp.edu.br

EDITOR IN CHIEF: Dulce Barbosa ASSOCIATE EDITOR: Priscilla Broca

Submission: $09-18-2020$

Approval: $04-02-202$

\begin{abstract}
Objective: Reflect on the implications of COVID-19 for the nursing care of pediatric oncology patients. Methods: Theoretical and reflective essay, based on recent scientific publications and expert recommendations on the care of pediatric patients under cancer treatment in the context of the current pandemic. Results: Reflected on the involvement of the pediatric population in general by COVID-19, the vulnerability of pediatric oncology patients to the complications of the disease and the likely challenges for their care. The pandemic demanded a rapid adaptation of health services in terms of patient care flow, care protocols, infection prevention measures, and redefinition of cancer therapy, with repercussions for professionals, patients, and their families. Final considerations: It is not yet known how often or how severely children with cancer have been affected by COVID-19, but therapeutic and care adaptations for the maintenance of these patients' treatment in the pandemic context are noted.

Descriptors: Coronavirus Infections; Neoplasms; Pediatric Nursing; Child; Adolescent.
\end{abstract}

\section{RESUMO}

Objetivo: refletir sobre as implicações da COVID-19 para os cuidados de enfermagem com pacientes oncológicos pediátricos. Métodos: ensaio teórico-reflexivo, a partir de publicações científicas recentes e recomendações de especialistas sobre o cuidado com pacientes pediátricos em tratamento oncológico no contexto da atual pandemia. Resultados: refletiu-se sobre o acometimento da população pediátrica em geral pela COVID-19, a vulnerabilidade dos pacientes pediátricos oncológicos às complicações da doença e os prováveis desafios para seu cuidado. A pandemia exigiu uma rápida adequação dos serviços de saúde quanto a fluxo de atendimento de pacientes, protocolos assistenciais, medidas de prevenção de infecção e redefiniç̧ão da terapêutica oncológica, com repercussões para os profissionais, pacientes e suas famílias. Considerações finais: Ainda não se sabe com que frequência ou gravidade crianças com câncer têm sido afetadas pela COVID-19, porém notam-se adaptações terapêuticas e assistenciais para a manutenção do tratamento desses pacientes no contexto de pandemia. Descritores: Infecções por Coronavírus; Neoplasias; Enfermagem Pediátrica; Criança; Adolescente.

\section{RESUMEN}

Objetivo: Reflejar acerca de implicaciones de COVID-19 a los cuidados de enfermería con pacientes oncológicos pediátricos. Métodos: Ensayo teórico-reflexivo, basado en publicaciones científicas recientes y recomendaciones de especialistas acerca del cuidado con pacientes pediátricos en tratamiento oncológico del contexto de la actual pandemia. Resultados: Reflejó acerca del acometimiento de la población pediátrica en general por COVID-19, la vulnerabilidad de pacientes pediátricos oncológicos a las complicaciones de la enfermedad y probables desafíos para su cuidado. La pandemia exigió una rápida adecuación de los servicios de salud cuanto al flujo de atención de pacientes, protocolos asistenciales, medidas de prevención de infección y redefinición de la terapéutica oncológica, con repercusiones a los profesionales, pacientes y sus familias. Consideraciones finales: Aún no se sabe con que frecuencia o gravedad niños con cáncer son afectados por COVID-19, pero perciben adaptaciones terapéuticas y asistenciales a la manutención del tratamiento de esos pacientes del contexto de pandemia.

Descriptores: Infecciones por Coronavirus; Neoplasias; Enfermería Pediátrica; Niño; Adolescente. 


\section{INTRODUCTION}

The COVID-19 is an acute respiratory infection caused by the severe acute respiratory syndrome coronavirus 2 (SARS-CoV-2). Coronaviruses are part of a large family of viruses that cause respiratory diseases in humans, which can range from mild, such as the common cold, to more severe conditions with high mortality rates, such as severe acute respiratory syndrome (SARS), detected in 2003 on the Asian continent, and Middle East respiratory syndrome (MERS-CoV), which dates back to $2012^{(1)}$.

The outbreak of COVID-19 was first reported in Wuhan, China in December 2019. The disease quickly spread to Asia, the Middle East, Europe, North America, and other parts of the world. On January 30, 2020, the World Health Organization (WHO) deemed COVID-19 a public health emergency of international importance, and on March 11,2020, it was declared a pandemic, which quickly became a global health crisis $^{(1-2)}$.

Although statistics show that children, compared to adults, are less likely to develop severe forms of the disease ${ }^{(3)}$, studies indicate that infants and preschool children may present severe clinical manifestations of the disease, due to the immaturity of the immune system in these age groups ${ }^{(2)}$. Another group considered vulnerable is that of children who already have some pre-existing chronic disease and/or are in a state of immunosuppression. Among these, we highlight pediatric oncology patients being treated with cytotoxic therapies, especially myeloablative ones, which require administration of high doses of immunosuppressive drugs ${ }^{(2-3)}$.

Given the current scenario and the importance of the continuity of treatment of these patients in specialized hospitals, this reflective study started with the following question: Based on the scientific evidence published so far, what can be learned about the repercussions of the COVID-19 pandemic for children in cancer treatment and what are the likely implications for nursing care?

\section{OBJECTIVE}

To reflect on the implications of the current pandemic of COVID-19 for the nursing care of pediatric oncology patients.

\section{METHODS}

This is a theoretical and reflective essay, based on recent scientific publications and expert recommendations on the care of pediatric patients under cancer treatment in the context of the current pandemic. Theoretical-reflective essays can be literary or scientific, the former being characterized by freedom in writing and strong subjectivity of the author, while the latter aims to promote the circulation of recent research results, with reflective content and that will serve as a starting point for future technical work ${ }^{(4)}$.

One of the purposes of essays is to gather and convey, in a concise manner, information based on the knowledge disseminated on a given subject ${ }^{(4)}$. In this sense, the present study methodically gathers and exposes the limited evidence on the behavior of COVID-19 in childhood, its risks and probable repercussions for pediatric patients undergoing oncologic treatment, as well as discusses them in light of the growing knowledge on the subject and the authors' expertise in the areas of infectious diseases and pediatric oncology. The reflective text has been divided into two synthetic categories, presented below: The affliction of the pediatric population by COVID-19 and its current outcomes; and Pediatric oncology patients and their vulnerability to COVID-19 complications, in addition to the subcategory: Likely challenges for the care of children with cancer in the pandemic scenario of COVID-19.

\section{THE INVOLVEMENT OF THE PEDIATRIC POPULATION BY COVID-19 AND ITS CURRENT OUTCOMES}

There are few cases of children infected with COVID-19 in different countries compared to the proportion of infected adults, especially regarding the outcome death. Although less prone to a worse prognosis, the risk of a child becoming infected resembles that of an adult ${ }^{(5)}$. Recent literature data indicate positive results for SARS-CoV-2 in about $2 \%$ of the population under the age of 19 years, in countries such as China and the United States ${ }^{(5-6)}$. This information comes from studies with small samples and has allowed us to observe that none of the children had pre-existing diseases, $65 \%$ had symptoms common to other respiratory diseases, $26 \%$ had mild respiratory symptoms, and $9 \%$ were asymptomatic. The most common symptoms observed were fever and cough ${ }^{(6)}$. Until now, the protective factors present in children and that hinder the evolution to the most severe forms of the disease are unknown.

In March 2020, a systematic review was published that gathered evidence on COVID-19 in the pediatric population. Up to that point, the highest number of positive cases in this population had been reported in China, and of the 44,672 confirmed cases in individuals up to 19 years of age, $0.9 \%$ were diagnosed in children under 10 years of age at diagnosis ${ }^{(7)}$.

In Brazil, by May 2020, about 130 deaths were registered in individuals aged zero to 19 years. It is noteworthy that most of the deaths occurred in older children, aged over ten years, and that these numbers underestimate the true rates of deaths from the disease, due to non-confirmation or underreporting of cases and outcomes. It is believed that the low case rates may be due to intrinsic factors of this population or refer to the underreporting of asymptomatic or oligosymptomatic cases, since most infected individuals in this age group do not manifest severe symptoms $s^{(5,8)}$.

Currently, medicine has drawn attention to more severe cases in childhood. In March 2020, one of the cases of COVID-19 diagnosed in a 10-year-old child, confirmed by reverse transcription polymerase chain reaction (RT-PCR) testing, progressed to major renal complications, showing that the disease is capable of exceeding the respiratory complications initially reported in this population $^{(7)}$. New clinical presentations of COVID-19 in children and adolescents still include multisystemic inflammatory syndrome, with manifestations similar to those seen in typical Kawasaki syndrome, incomplete Kawasaki or toxic shock syndrome. Some of these episodes evolve into cardiogenic shock, causing these children to require hospitalization in pediatric intensive care units ${ }^{(9)}$.

There is still a scarcity of records on the evolution of children with comorbidities, as in the case of pediatric oncology patients. 
There is insufficient evidence on the severity of the disease in patients with this profile, which limits the appropriate identification of risks for complications, besides hindering the knowledge about the outcomes of diagnosed cases $^{(2-3)}$. Therefore, the lack of reliable data compromises the planning of health actions in order to preserve these patients from infection by SARS-CoV-2, in a context where there is an urgent need to ensure continuity of treatment, clinical follow-up and care for these patients in health services.

\section{PEDIATRIC ONCOLOGY PATIENTS AND THEIR VULNER- ABILITY TO COMPLICATIONS OF COVID-19}

The first study on the behavior of SARS-CoV-2 infection in children with cancer indicated a low mortality rate from COVID-19 in these patients. Between the months of March and April, 178 children and adolescents with cancer were tested, most of them male $(n=107)$, with a mean age of 11.1 years. Of these, $20(11.2 \%)$ tested positive for the disease ${ }^{(9)}$. This study served to profile the infected patients, indicating that only one of them required hospitalization as a result of COVID-19. The others who tested positive had been admitted to the service for fever and neutropenia, for other complications of the treatment, or for administration of chemotherapy ${ }^{(10)}$.

Although these results do not predict that pediatric oncology patients are more susceptible to infection and severe forms of the disease, societies and associations dedicated to pediatric oncology treatment have been manifesting themselves in order to alert to a group considered extremely vulnerable, composed of children receiving chemotherapy in the induction phase, which usually includes high doses of steroids; children being treated for leukemias and lymphomas - very frequent diagnoses in this population ${ }^{(2)}$; children receiving chemotherapy for refractory leukemias and lymphomas; those who have undergone hematopoietic stem cell transplantation in the last 12 months; and pediatric patients being treated with CART cell gene therapy ${ }^{(3,6)}$.

In addition to the complications presumed in this population, health professionals should be aware of data indicating the increased possibility of co-infections, that is, the concomitant infection by COVID-19 and other microorganisms, especially in the transplanted population.

\section{Likely Challenges for the Care of Children with Cancer in the Context of the COVID-19 Pandemic}

A study ${ }^{(11)}$ points out that, at the beginning of the pandemic, parents were faced with the possibility of postponing the treatment of their children. This and other uncertainties can be very stressful in a disease such as childhood cancer, whose biological behavior makes the adoption of expectant behaviors unfeasible. As there is no forecast as to the duration of the pandemic context, especially in Brazil, specialized hospitals have redefined the protocols of oncologic treatment.

It is worth reflecting on how the data already presented impact on the care and continuity of treatment of children already diagnosed with cancer or who will be diagnosed during the pandemic period of COVID-19. In care settings, health professionals, among them nurses, have recently been dealing with the consequences of the pandemic, especially the increase in family anxiety ${ }^{(2)}$.

Within the concept of vulnerability of these patients in the context of a pandemic, it is worth mentioning the repercussions, not necessarily clinical, but equally relevant for nursing care to this clientele and their families. Although recent statistics do not indicate a greater severity and lethality of the cases of COVID-19 in the pediatric cancer population ${ }^{(6-7)}$, parents feel that their children are more vulnerable and, therefore, should be the target of greater vigilance. It is noteworthy that these parents already face a constant battle against the infectious risk to which these children are prone throughout their cancer treatment ${ }^{(11)}$.

The vulnerability, inherent to becoming ill with a malignant disease, becomes even more pronounced in the pandemic context and adds more restrictive measures in home care and social interaction of patients and their families. Moreover, the search for reference services, often necessary due to the various complications of the disease and its treatment, may be postponed due to the fear of exposure to COVID-19 and its most recent variants ${ }^{(11)}$.

Another challenge refers to the inconstancy of the information that reaches families. The fickleness of information leads to inconsistencies and difficulties in the management of the disease and the treatment of the child. One example is the lower demand for emergency services by parents of children with cancer during the pandemic. This is alarming considering the range of rapidly developing complications that these children are susceptible to.

In addition to considering the access of children to medical care in this context of uncertainty, it is essential to offer constant support to them and their families, so that the initiation of treatment, its continuation or completion occurs safely. To this end, it is essential to provide updated and reliable information about the prevention and control of COVID-19, such as the identification of signs and symptoms of the disease, guidance on hand hygiene, mask use, respiratory etiquette, and physical distancing at home. Consultations, including nursing consultations, should be of limited duration, and some recommendations from specialized institutions include screening patients and families by telephone to assess the need to attend the emergency department of the institution where treatment occurs ${ }^{(2,6)}$.

In hospitalizations, when indispensable, it is suggested that children be admitted to individual rooms, the number of external visits be limited, and only one parent accompany them during hospitalization. It is recommended to avoid visits by siblings and other family members, however, situations must be considered in which other combinations may be necessary, such as for children in end-of-life situations, newly diagnosed or relapsing. To deal with the emotional impact caused by limited communication with significant people, studies suggest the use of alternative forms of communication, such as cell phone and voice and video message communication ${ }^{(2,6)}$. Furthermore, in cases of infected children whose isolation is essential, there must be, in addition to clinical support, emotional support for patients and families ${ }^{(2)}$.

The most recent recommendations regarding the care activities of nursing professionals foresee that those who are caring for neutropenic patients should not care for other confirmed or suspected COVID-19 patients. Those exposed to the disease should not care for neutropenic patients for at least 14 days and, 
as observed in health services in general, employees who tested positive should return to their activities according to the protocol established by the institution where they work ${ }^{(2-3,12)}$.

It is also imperative to reflect on the frontline workforce in the fight against COVID-19, particularly with regard to occupational health and safety. By the very nature of their work, health care workers are more exposed to SARS-CoV-2. According to the WHO report, as of April 8, 2020, 52 countries reported 22,073 cases of COVID-19 among healthcare workers. China reported 1,688 (3.8\%) infections among healthcare workers and five deaths in February 2020. In Italy, an April 10, 2020 situation report reported 15,314 infections among healthcare workers, equivalent to $11 \%$ of all infections at that time ${ }^{(1)}$.

Nurses who work in pediatric oncology, in addition to already living with high levels of stress, emotional overload and compassion fatigue, face greater challenges in providing care to children with cancer and their families in the pandemic scenario. In terms of practical issues, the administration of chemotherapy, for example, demands the rational and optimal use of Personal Protective Equipment (PPE), which must be adequate both for the administration of chemotherapy drugs and for individual protection against COVID-19(3). Expert societies, such as the Oncology Nursing Society (ONS), have recommended in constantly updated guidelines that a mask with face and eye protection be worn when there is a likelihood of splashing or for cleaning up cytotoxic drug spills; that a single nurse be assigned to perform all chemotherapy drug disconnections, and for less harmful drugs, that gloves (without an apron) be worn) ${ }^{(2-3,6,12)}$. Such suggestions consider the scarcity of materials and their high cost of acquisition by the institutions, as well as the reduction of their availability, due to the generalized use of PPE in health services that have been dedicated to the care of infected patients, in particular.

Nursing plays a fundamental role, not only in the provision of clinical care, but also in the supervision of actions, education, support to family members and other professionals, as well as in the reduction of risks for the patient, his family and other members of the health team. Thus, it is important that health institutions invest in initiatives to maintain the quality of care and the mental health of their professionals, such as the continuing education of professionals on updated strategies for prevention and infection control, as for precautions and isolation, hand hygiene, proper use of PPE, cleaning and disinfection of surfaces and environment. It is also necessary to implement measures such as patient screening, which are imperative for the protection of patients, their families, and professionals. In addition to these measures, the WHO recommends complementary measures ${ }^{(1)}$, such as, for example, the offer of psychosocial support, the adequate number of professionals and clinical rotation with the purpose of reducing the risk of burnout syndrome and aiming at a safer and healthier work environment that respects the rights of workers and provides adequate conditions that will reverberate in the quality of the care offered.

\section{FINAL CONSIDERATIONS}

This study proposed a reflection about the implications of the current pandemic of the new coronavirus for nursing care of pediatric oncology patients. As a limitation of this reflective study, we highlight the insufficiency of studies that report on the frequency or severity with which pediatric oncology patients have been affected by COVID-19 and the outcomes of such infections, but therapeutic and care adaptations are described for the maintenance of the treatment of these patients in the context of pandemic.

Although the susceptibility of these children to more severe forms of the disease has not yet been confirmed in studies, caution persists in sparing them from infection by COVID-19, because as long as there is no known drug to prevent and treat the infection, the best protection will be provided by interventions that reduce the risk of transmission. The possibility of infection afflicts the family members, who need consistent and updated information about the risks to which their children are exposed, as well as clarification regarding the therapeutic routine in this scenario of uncertainty.

The issues raised by this reflection inform about important implications for the pediatric oncology patient and can assist nurses in meeting the current and emerging needs of this clientele and their families. Nurses play a fundamental role in this scenario, to the extent that they identify the needs of each patient/family and, together with the multidisciplinary team, are able to propose interventions and adaptations. As far as nurses are concerned, COVID-19 seems to have changed the work dynamics of the professionals involved in the assistance to these patients, since it demands the role of educating, in addition to caring, for both the child with cancer and its family. As an aggravating factor, nurses still live daily with exposure to the disease and with the fear of being vehicles of transmission, besides facing great occupational and emotional overload.

The most current recommendations, from researchers and specialized societies, highlight the protection of children with cancer, their families and professionals dedicated to their care. Only actions focused on these pillars - child, professional, and family - can contribute to the provision of treatment to newly diagnosed patients and ensure the continuity of specialized treatment and the promotion of occupational health, which will reflect in better quality care and comprehensive care to all involved in pediatric oncology treatment.

\section{REFERENCES}

1. World Health Organization (WHO). Timeline of WHO's response to COVID-19 [Internet]. Geneve: WHO; 2020 [cited 2020 Sep 5]. Available from: https://www.who.int/news-room/detail/29-06-2020-covidtimeline

2. Sullivan M, Bouffet E, Rodriguez-Galindo C, Luna-Fineman S, Khan MS, Kearns P, et al. The COVID-19 pandemic: a rapid global response for children with cancer from SIOP, COG, SIOP-E, SIOP-PODC, IPSO, PROS, CCI, and St Jude Global. Pediatr Blood Cancer. 2020;67(7):e28409. https://doi.org/10.1002/pbc.28409 
3. Kotecha RS. Challenges posed by COVID-19 to children with cancer. Lancet Oncol. 2020;21(5):e235. https://doi.org/10.1016/ S1470-2045(20)30205-9

4. Figueiredo ADC. A arte de ensaiar com uma perspectiva científica. Rev Palimpsesto UERJ. 2012;11(15):1-14. https://doi.org/10.12957/ palimpsesto

5. Zimmermann P, Curtis N. Coronavirus infections in children including COVID-19: an overview of the epidemiology, clinical features, diagnosis, treatment and prevention options in children. Pediatr Infect Dis J. 2020;39(5):355-68. https://doi.org/10.1097/ INF.0000000000002660

6. Bouffet E, Challinor J, Sullivan M, Biondi A, Rodriguez-Galindo C, Pritchard-Jones K. Early advice on managing children with cancer during the COVID-19 pandemic and a call for sharing experiences. Pediatr Blood Cancer. 2020;67(7):e28327. https://doi.org/10.1002/pbc.28327

7. Ludvigsson JF. Systematic review of COVID-19 in children shows milder cases and a better prognosis than adults. Acta Paediatr. 2020;109(6):1088-1095. https://doi.org/10.1111/apa.15270

8. Almeida FJ, Olmos RD, Oliveira DB, Monteiro CO, Thomazelli LM, Durigon EL, et al. Hematuria associated with SARS-CoV-2 infection in a child. Pediatr Infect Dis J. 2020;39(7):e161. https://doi.org/10.1097/INF.0000000000002737

9. Jones VG, Mills M, Suarez D, Hogan CA, Yeh D, Bradley Segal J, et al. COVID-19 and Kawasaki disease: novel virus and novel case. Hosp Pediatr. 2020;10(6):537-40. https://doi.org/10.1542/hpeds.2020-0123

10. Boulad F, Kamboj M, Bouvier N, Mauguen A, Kung AL. COVID-19 in children with cancer in New York City. JAMA Oncol. 2020:e202028. https://doi.org/10.1001/jamaoncol.2020.2028

11. Steinberg DM, Andresen JA, PahI DA, Licursi M, Rosenthal SL. "I've weathered really horrible storms long before this...": the experiences of parents caring for children with hematological and oncological conditions during the early months of the COVID-19 pandemic in the U.S. J Clin Psychol Med Settings. 2021;25:1-8. https://doi.org/10.1007/s10880-020-09760-2.

12. Burki TK. Cancer guidelines during the COVID-19 pandemic. Lancet Oncol. 2020;21(5):629-30. https://doi.org/10.1016/ S1470-2045(20)30217-5 